\title{
Psychiatric, demographic and personality characteristics of elderly sex offenders
}

\author{
S. FAZEL, ${ }^{1}$ T. HOPE, I. O’DONNELL AND R. JACOBY \\ From the University of Oxford Department of Psychiatry, Warneford Hospital and Department of Public \\ Health and Primary Care, Institute of Health Sciences, University of Oxford; and Institute of Criminology, \\ Faculty of Law, University College Dublin, Dublin, Ireland
}

\begin{abstract}
Background. Psychiatric disorders are purported to play a role in the aetiology of violent crime, but evidence for their role in sexual offending is less clear. The authors investigated the prevalence of psychiatric morbidity and personality disorders in elderly incarcerated sex offenders compared with elderly non-sex offenders.
\end{abstract}

Method. One hundred and one sex offenders and 102 non-sex offenders aged over 59 years were interviewed using standardized semi-structured interviews for psychiatric illness (the Geriatric Mental State) and the personality disorder (Structured Clinical Interview for DSM-IV personality disorders). Data on demographic, offence and victim characteristics were collected.

Results. Six per cent of the elderly sex offenders had a psychotic illness, 7\% a DSM-IV major depressive episode and $33 \%$ a personality disorder; and $1 \%$ had dementia. These prevalence figures were not different from the elderly non-sex offenders interviewed in this study. Differences emerged at the level of personality traits with sex offenders having more schizoid, obsessive-compulsive, and avoidant traits, and fewer antisocial traits compared with non-sex offenders.

Conclusions. Elderly sex offenders and non-sex-offenders have similar prevalence rates of mental illness. However, elderly sex offenders have increased schizoid, obsessive-compulsive, and avoidant personality traits, supporting the view that sex offending in the elderly is associated more with personality factors than mental illness or organic brain disease.

\section{INTRODUCTION}

Although an increasing body of research exists on the relationship between violent crime and mental illness (Tilhonen et al. 1997; Brennan et al. 2000), the relationship between sex offending and mental disorder is less clear. This information is important in aiding the understanding of the mechanisms and aetiological factors that are associated with sex offending, and in contributing to risk assessment, predicting recidivism, and selecting treatment. Such research may also assist in public policy development. Recently, legislative proposals for the civil commitment of sex offenders in the US and the

${ }^{1}$ Address for correspondence: Dr Seena Fazel, University of Oxford Department of Psychiatry, Warneford Hospital, Oxford OX3 7JX.
UK, particularly of 'sexual predators', have been controversial and concern has been expressed that they have not been supported by scientific evidence (Zonana, 1997).

Preliminary research on the psychiatric characteristics of sex offenders has been inconclusive, with some studies suggesting high rates of psychiatric morbidity (Abel et al. 1988; McElroy et al. 1999) and others reporting low rates (Henn et al. 1976). This research has been difficult to interpret because of the use of referred samples and the lack of non-sex offender comparison groups. Without such comparison groups, research on sex offenders may simply reflect nonspecific offender characteristics. We are not aware of any clinical research on the psychiatric morbidity of sex offenders that has used a nonsex offender group for comparison. 
Elderly sex offenders are not a trivially small group. In Western countries where information is available, about half the male sentenced prison population of the over 59s are sex offenders (Greenfield, 1997; Home Office, 1998; Uzoaba, 1998). In a community treatment programme in England, elderly sex offenders constituted around $15 \%$ of referrals (Mezey et al. 1991). We report in this paper data comparing the psychiatric characteristics of 101 men aged over 59 years who were sentenced for sex offences with 102 men sentenced for non-sexual offences. These data were collected as part of a wider study of the psychiatric characteristics of elderly male prisoners (Fazel et al. 2001). Elderly sex offenders are an important group to study for three reasons. First, sex offences are proportionately important in the elderly: in the over 59 age group, sex offences constitute $21 \%$ of all convictions (Jacoby, 1997). Secondly, there has been no research on elderly sex offenders that has been based on clinical interviews. Thirdly, it has been hypothesized that there is an increased prevalence of organic brain disorders in elderly sex offenders - case note studies have found 13-14\% with this diagnosis (Henn et al. 1976; Hucker \& Ben-Aron, 1985) - but this has not been tested in any clinical study.

\section{METHOD}

\section{Prisons and prisoners}

Sentenced men aged 60 years and older are scattered widely across over 90 prisons in England and Wales. We selected prisons that were within 100 miles of Oxford and had at least 10 elderly prisoners. Fifteen prisons met these criteria, and the elderly prisoners inside them were representative of all elderly inmates across England and Wales in terms of time served, offence category, and type of prison (Fazel et al. 2001). All sentenced inmates in these prisons aged 60 and over were approached, and informed that the survey was confidential and voluntary. Written consent was obtained before the interview. Interviews were conducted in private within the prison between April 1999 and March 2000 by a specialist registrar psychiatrist (S. F.) who had received training in the use of the diagnostic instruments administered and was blind to diagnoses recorded in the medical notes and index offence when administering these instruments. The project was approved by the Prison Health Service Research Ethics Committee of England and Wales.

\section{Instruments}

The following standardized instruments were used.

Geriatric Mental State schedule (GMS)

This is a semistructured clinical interview designed to assess the mental state of the elderly in the community. AGECAT, the computerized diagnostic schedule which processes GMS data, has been shown to accord with diagnoses made by experienced psychiatrists and correspond to DSM diagnoses (Copeland et al. 1988; Ames et al. 1994). Data on mood disorders in this study were converted to DSM-IV criteria for major depressive episode using a standard algorithm at the University of Liverpool's Institute for $\mathrm{Hu}-$ man Ageing. The GMS does not assess personality disorders.

Structured Clinical Interview for DSM-IV axis II personality disorders (SCID-II)

The Structured Clinical Interview for DSM-IV axis II personality disorders (SCID-II) was administered after the GMS (First et al. 1997). Each personality disorder category is assessed by a series of specified questions which can meet threshold or subthreshold criteria. For a diagnosis of personality disorder, a specified number of threshold items must be met (usually four threshold items out of a possible seven or eight). Trait scores were calculated by multiplying each threshold item by two and adding this to the number of subthreshold items.

\section{Mini-Mental State Examination and National Adult Reading Test}

Two brief neuropsychological tests were administered: the Mini-Mental State Examination (MMSE) as a screen for cognitive impairment (Folstein et al. 1975), and the National Adult Reading Test (NART), a valid reliable index of pre-morbid IQ in elderly individuals (O'Carroll, 1995).

\section{Semi-structured interview}

Information on the offence was gathered using a semi-structured interview based on that used by 
Clark \& Mezey (1997). This section was not administered to non-sex offenders.

\section{Procedure}

After the clinical diagnostic interview, criminological information was gathered from the local prison database. We were unable to date reliably the date of the index sex offence as this database only provided information on the date of conviction, and some offenders had been convicted for offences committed many years previously. In addition, the prison inmate record was read to establish the presence of a past psychiatric history (including in-patient and outpatient psychiatric contact, any recorded history of deliberate self-harm, any recorded history of alcohol or substance dependence). Monthly meetings were held with a steering committee of senior academic psychiatrists (R. J. and T. H.) where diagnostic issues were reviewed.

\section{Statistical analysis}

Data were entered into SPSS that generated descriptive statistics and comparisons of means. Standard chi-squared tests and Student's $t$ tests were used to compare categorical and continuous data respectively.

\section{RESULTS}

A total of 233 men were approached, of whom 203 were interviewed, representing $19 \cdot 2 \%$ of the sentenced population of men aged 60 and over in England and Wales. The 30 men (14.8\%) who refused consent did not differ significantly from those who gave consent with regard to age $(65.6$ $($ S.D. $=4.8)$ v. $65.5($ S.D. $=4.8))$ or past psychiatric history recorded in their records $(40 \%$ v. $48 \%$ ) but had been in prison longer (median length $=59 v .16$ months, $z=3.40, P<0.001)$. Of the 203 men interviewed, 101 were sex offenders.

\section{Demographics}

The mean age of the sex offenders was 65.9 (s.D. $=4 \cdot 7$, range $60-88$ ), similar to the other offenders whose mean age was $65 \cdot 1$ (S.D. $=4 \cdot 9$, range 60-83) (see Table 1). The median time spent in prison was not significantly different for those who had committed sex offences (15 months) compared with those who did not commit sex offences (22 months, $z=-1 \cdot 40$, $P=0 \cdot 16)$. Compared with non-sex offenders, sex
Table 1. Demographic information and current psychiatric diagnoses of elderly sex offenders and elderly non-sex offenders

\begin{tabular}{|c|c|c|}
\hline Variable & $\begin{array}{c}\text { Sex } \\
\text { offenders } \\
N\end{array}$ & $\begin{array}{c}\text { Other } \\
\text { prisoners } \\
N\end{array}$ \\
\hline \multicolumn{3}{|l|}{ Age band } \\
\hline $60-69$ & 82 & 89 \\
\hline $70-79$ & 17 & 11 \\
\hline$\geqslant 80$ & 2 & 2 \\
\hline \multicolumn{3}{|l|}{ Ethnic origin } \\
\hline Non-white & 5 & $19 *$ \\
\hline \multicolumn{3}{|l|}{ Marital status at time of offence } \\
\hline Married & 15 & 17 \\
\hline Divorced/separated & 42 & 48 \\
\hline Widowed & 7 & 6 \\
\hline Single & 31 & 28 \\
\hline Unknown & 9 & 0 \\
\hline \multicolumn{3}{|l|}{ Professional status } \\
\hline $\begin{array}{l}\text { Professional, managerial, } \\
\text { or intermediate }\end{array}$ & 11 & 23 \\
\hline Skilled and semi-skilled manual & 75 & 67 \\
\hline Unskilled & 15 & 11 \\
\hline Unknown & 1 & 0 \\
\hline Employed at time of offence & 33 & $68 *$ \\
\hline Last employment car/truck driver & 23 & $5 * * *$ \\
\hline Past psychiatric history & 42 & $56^{*}$ \\
\hline Psychoses & 6 & 4 \\
\hline Dementia & 1 & 1 \\
\hline DSM-IV major depressive episode & 7 & 8 \\
\hline Substance abuse/dependence & 1 & 9 \\
\hline \multicolumn{3}{|l|}{ DSM-IV personality disorder } \\
\hline Antisocial & 5 & 12 \\
\hline Avoidant & 11 & 6 \\
\hline Obsessive-compulsive & 10 & 6 \\
\hline Schizoid & 10 & 3 \\
\hline Paranoid & 4 & 3 \\
\hline Not otherwise specified & 1 & 4 \\
\hline Any personality disorder & 33 & 28 \\
\hline Total & 101 & 102 \\
\hline
\end{tabular}

offenders were more likely to be white $\left(\chi^{2}=9 \cdot 3\right.$, $\mathrm{df}=3, P=0.03)$, unemployed at the time of their offence $\left(\chi^{2}=6 \cdot 3, \mathrm{df}=2, P=0.04\right)$, have worked most recently as a car or truck driver $\left(\chi^{2}=13 \cdot 4, \mathrm{df}=1, P<0.001\right)$ and have a past psychiatric history recorded in their medical notes $\left(\chi^{2}=4.8, \mathrm{df}=1, P=0.03\right)$. The age of conviction for the index offence of the sex offenders was significantly older $(62.7$ years for the sex offenders (s.D. $=7 \cdot 3$ ) compared to 57.9 for the others (S.D. $=10 \cdot 4$ ); $t=3.84, \mathrm{df}=201$, $P<0.001)$. The marital status of the two groups was similar. Other demographic information is presented in Table 1. 
Table 2. Personality trait scores of elderly sex offenders and elderly non-sex offenders

\begin{tabular}{lcccc}
\hline \hline Trait & $\begin{array}{c}\text { Sex offender } \\
\text { Mean (S.D.) }\end{array}$ & $\begin{array}{c}\text { Non-sex offender } \\
\text { Mean (s.D.) }\end{array}$ & $P$ & $t(\mathrm{df}=201)$ \\
\hline Avoidant & $2 \cdot 0(3 \cdot 2)$ & $1 \cdot 1(2 \cdot 9)$ & $<0 \cdot 05$ & $2 \cdot 13$ \\
Schizoid & $2 \cdot 9(2 \cdot 9)$ & $1 \cdot 2(1 \cdot 9)$ & $<0 \cdot 0001$ & $5 \cdot 06$ \\
Paranoid & $0 \cdot 9(2 \cdot 0)$ & $1 \cdot 2(2 \cdot 3)$ & $\mathrm{NS}$ & $1 \cdot 02$ \\
Obsessive-compulsive & $3 \cdot 1(3 \cdot 1)$ & $2 \cdot 1(2 \cdot 7)$ & $0 \cdot 02$ & $2 \cdot 42$ \\
Antisocial & $2 \cdot 1(2 \cdot 1)$ & $2 \cdot 8(2 \cdot 9)$ & $<0 \cdot 05$ & $2 \cdot 08$ \\
\hline \hline
\end{tabular}

Trait scores were calculated by multiplying each threshold item for a personality disorder category on the SCID-II by two and adding this to the number of subthreshold items.

\section{Psychiatric characteristics}

Psychiatric diagnoses are presented in Table 1. No significant differences were found between the sex offenders and other offenders for diagnoses of psychotic illness, major depressive episode, organic disorder (dementia) and personality disorder. Sex offenders were less likely to be substance abusers. There were no individuals in this study who were diagnosed with dependent, schizotypal, histrionic, narcissistic, or borderline personality disorders. As the number of sex offenders and non-sex offenders with personality disorders was small, personality disorder differences were further explored by comparing personality traits (Table 2). The largest differences were found in the presence of more schizoid and obsessive-compulsive traits in sex offenders. Smaller differences were found in sex offenders possessing more avoidant and fewer antisocial traits.

The mean MMSE score of the sex offenders was $28.0($ S.D. $=2 \cdot 3)$, which was similar to those of the non-sex offenders (MMSE $=27 \cdot 9$, s.D. $=$ 2.6). However, there was a significant difference in the NART estimated IQ of the two groups: the mean NART score of the sex offenders was 95.5 (S.D. $=14 \cdot 2$ ) and those of the non-sex offenders was $100 \cdot 8$ (s.D. $=13 \cdot 8)(t=2 \cdot 63, \mathrm{df}=$ $190, P=0 \cdot 009$ ).

\section{Offences and victims}

The offences of the sex offenders were rape and attempted rape (41 cases), indecent assault and gross indecency $(N=38)$, buggery $(N=17)$, incest $(N=2)$ and other $(N=3)$. The offences of the other prisoners were for violent crimes $(N=50)$, drug-related $(N=29)$, theft $(N=7)$, fraud $(N=5)$, robbery $(N=4)$ and other $(N=$ 7). Select offence and victim characteristics of the sex offenders in this sample are presented in
Table 3. Offence characteristics of sex offenders

\begin{tabular}{|c|c|c|}
\hline Variable & & $\begin{array}{l}\text { Known } \\
\text { cases } \%\end{array}$ \\
\hline $\begin{array}{l}\text { Relationship to victim } \\
\text { (unknown } N=6 \text { ) }\end{array}$ & $\begin{array}{l}\text { Father/grandfather } \\
\text { Stepfather } \\
\text { Relative } \\
\text { Acquaintance } \\
\text { Stranger }\end{array}$ & $\begin{array}{r}34 \\
13 \\
4 \\
40 \\
9\end{array}$ \\
\hline $\begin{array}{l}\text { Sex of victims } \\
\text { (unknown } N=5 \text { ) }\end{array}$ & $\begin{array}{l}\text { Male only } \\
\text { Female only } \\
\text { Both sexes }\end{array}$ & $\begin{array}{l}23 \\
65 \\
13\end{array}$ \\
\hline $\begin{array}{l}\text { Age of victims at start of } \\
\text { offence (unknown } N=8 \text { ) }\end{array}$ & $\begin{array}{l}<11 \\
\geqslant 11\end{array}$ & $\begin{array}{l}47 \\
53\end{array}$ \\
\hline $\begin{array}{l}\text { Number of victims } \\
\text { (unknown } N=5 \text { ) }\end{array}$ & $\begin{array}{l}1 \\
2-4 \\
>4\end{array}$ & $\begin{array}{l}38 \\
49 \\
14\end{array}$ \\
\hline $\begin{array}{l}\text { Length of time offending } \\
\text { (current offences) } \\
\text { (unknown } N=6 \text { ) }\end{array}$ & $\begin{array}{l}<1 \text { year } \\
1-5 \text { years } \\
5-10 \text { years } \\
\geqslant 10 \text { years }\end{array}$ & $\begin{array}{r}47 \\
29 \\
6 \\
17\end{array}$ \\
\hline $\begin{array}{l}\text { Place of offences } \\
\text { (unknown } N=16 \text { ) }\end{array}$ & $\begin{array}{l}\text { Own home } \\
\text { Victim's home } \\
\text { Other }\end{array}$ & $\begin{array}{r}81 \\
7 \\
10\end{array}$ \\
\hline $\begin{array}{l}\text { Type of offence } \\
\text { (unknown } N=3 \text { ) }\end{array}$ & $\begin{array}{l}\text { Penetrative } \\
\text { Non-penetrative }\end{array}$ & $\begin{array}{l}46 \\
54\end{array}$ \\
\hline $\begin{array}{l}\text { Co-perpetrator } \\
\text { (unknown } N=9 \text { ) }\end{array}$ & $\begin{array}{l}\text { Involved in offence } \\
\text { Not involved }\end{array}$ & $\begin{array}{r}7 \\
93\end{array}$ \\
\hline $\begin{array}{l}\text { Recent stressors } \\
\text { (at time of offence) } \\
\text { (unknown } N=15 \text { ) }\end{array}$ & $\begin{array}{l}\text { Present } \\
\text { Not present }\end{array}$ & $\begin{array}{l}49 \\
51\end{array}$ \\
\hline
\end{tabular}

Table 3. Most of the sex offenders were the father, stepfather, grandfather, or an acquaintance of their victim; and had committed crimes on several girls, and usually alone in the offender's home.

A past history of childhood sexual abuse was disclosed by $29(33.0 \%)$ of the elderly sex offenders (no sexual abuse in 59, unknown 13). Self-reported early losses were described in 22 individuals (no early losses in 61, unknown 18). No comparative data were available on non-sex offenders. 


\section{Categories of sex offenders}

We compared those convicted of more aggressive acts - rape and buggery (58 individuals) - with those convicted of indecent assault and gross indecency (38 individuals). There were no differences in the rates of psychiatric illness between these two groups apart from being assigned a diagnosis of personality disorder. Twenty-five $(43.1 \%)$ of those convicted of rape and buggery had a diagnosis of personality disorder compared with six $(15.8 \%)$ who were convicted of indecent assault and gross indecency $\left(\chi^{2}=7 \cdot 83\right.$, $\mathrm{df}=1, P=0 \cdot 05)$. There were no significant differences in personality traits. However, those convicted of rape and buggery had lower MMSE $(27.8$ (S.D. $=1.6))$ and NART-estimated IQ scores $(92.5 \quad($ S.D. $=13 \cdot 2))$ than those convicted of indecent assault and gross indecency $(\mathrm{MMSE}=28.6 \quad($ S.D. $=1 \cdot 5), \quad t=2 \cdot 5, \quad \mathrm{df}=93$, $P=0.02 ; \mathrm{NART}=99 \cdot 7$ (S.D. $=15 \cdot 0), t=2 \cdot 4$, $\mathrm{df}=90, P=0 \cdot 02)$.

\section{DISCUSSION}

We report the first psychiatric study, as far as we are aware, of sex offenders (of any age group) that uses a non-sex offender comparison group. There were three main findings from this investigation of imprisoned male sex offenders aged 60 and over. First, high rates of psychiatric morbidity were detected: $6 \%$ had a psychotic illness, $7 \%$ a DSM-IV major depressive episode and $33 \%$ a DSM-IV personality disorder. Secondly, there were low rates of organic disorder $-1 \%$ had a clinical diagnosis of dementia. Thirdly, elderly sex offenders did not differ in psychiatric or personality disorder diagnoses from elderly non-sex offenders. However, at the level of personality traits, there were significant differences. Sex offenders had more schizoid traits in their personality (core features of which are social detachment and restricted emotionality), and we found trends that suggest that they had more obsessive-compulsive and avoidant traits, and fewer antisocial ones. Overall, these findings support the view that sex offending may be more related to personality factors than acute mental illness or organic brain disease. On tests of cognitive function, sex offenders had significantly lower estimated IQ scores compared with non-sex offenders con- firming a non-significant trend reported in a smaller study in 51 sexually aggressive men (Hucker et al. 1988). However, the estimated IQ score of the sex offenders in this study was within the normal range. Mini-mental state examination scores were similar in the two groups. The finding in this study that sex offenders had fewer substance abuse disorders should be interpreted cautiously as small numbers were involved, and the diagnosis of substance abuse disorders is complicated by a number of factors in the prison environment.

A limitation of this study was that it combined the different types of sex offender. We attempted to test the hypothesis that there are important differences between these categories by comparing the psychiatric characteristics of those who were convicted of more aggressive acts (rape and buggery) with those convicted of indecent assault and gross indecency. We found that those convicted of rape and buggery were more likely to be diagnosed with a personality disorder, and had lower estimated IQ and minimental state examination scores. Our finding that those convicted of rape and buggery were more likely to be diagnosed as personality disordered concurs with a review which concluded that rapists were more likely to be personality disordered than child molestors (Salter, 1988). A second limitation was that the non-sex offenders may not have been the ideal comparison group. Some of them may have committed sex offences in the past, and, as only the most serious offence was documented in their criminal records, it is possible that a number of those charged with violent offences had a sexual component to them. In addition, the personality characteristics of non-sex offenders may be unusual, in particular the presence of increased antisocial personality traits. A third issue is whether these findings are generalizable to all sex offenders, as the group of prisoners in this study constitutes the severer end of sexual criminals.

\section{Demographic findings}

There were significant differences in some demographic features of elderly sex offenders compared with other elderly offenders. Sex offenders were more likely to be white, unemployed at the time of their offence, and less likely to have a past psychiatric history recorded in their medical 
notes. The most significant difference was that the sex offenders' last main profession was more likely to be a driver of a car, van, or truck. This would accord with the finding that there were increased schizoid traits found in elderly sex offenders. One explanation for this association is that those with schizoid personality traits are more attracted to these professions. The nature of the occupation may itself contribute to the risk of sex offending. As it may involve long solitary periods, interpersonal skills may be eroded, and family and peer relationships may be damaged. It is also possible that itinerant professions offer sex offenders opportunities to commit crimes in various locations and evade detection by the police authorities there. The latter explanation is not supported by the fact that $81 \%$ of all the sex offenders in this study said that the place of the offence was their own home. However, as this is the offence for which they were most recently caught, it is possible that they had been sexually offending undetected during their work in the past. The marital statuses of sex offenders were similar to non-sex offenders. Thirty-one per cent of the sex offenders were single, markedly different from the UK population, where $7 \%$ of men aged over 65 are single (Office of Population, 1993). Other prison surveys in England and Wales have not reported the occupational background of their samples, although the proportion of sex offenders working at the time of their offence $(33 \%)$ in this study is similar to that of younger prisoners in the recent Office for National Statistics investigation which found that $44 \%$ of younger sentenced men were in current employment (Singleton et al. 1998).

Another study, using data from a survey of 85000 sex offenders in US state prisons, provides information on offence characteristics of younger sex offenders (average age 30-35 years) (Greenfield, 1997). With the caveat that this investigation is from the US and conducted in 1997, we found that the victims in the study reported here were more likely to be female, under 11 years old, and the perpetrator related to the victim as father, stepfather, or grandfather. The sex offenders in our sample were more likely to have multiple victims, offend in their own homes, and less likely to sexually assault strangers than in the US study. As our study relates to current charges only, it is unlikely that so many had been offending for less than 1 year $(47 \%)$ and had so few victims $(38 \%$ reported one victim). We found that elderly sex offenders disclosed that they had been sexually abused as children in $33 \%$ of cases. This compares with $35 \%$ reporting childhood sexual abuse in a treatment centre for sex offenders (Seghorn et al. 1987), and $28 \%$ of sex offenders in US prisons report physical or sexual abuse as children (Greenfield, 1997).

\section{Psychiatric diagnoses}

We found high rates of psychiatric morbidity in this sample of elderly sex offenders. Six per cent had a psychotic illness which, although not significantly different from the non-sex offenders studied, is consistent with the increased prevalence of severe psychiatric morbidity in other investigations of general prison populations in England and Wales (Gunn et al. 1991; Singleton et al. 1998). Other studies of the epidemiology of mental disorders in incarcerated sex offenders and elderly persons in the community provide useful comparative information. The largest study of the psychiatric diagnoses of sentenced adult male sex offenders in a general prison population was conducted in Canada using standardized semi-structured clinical interviews generating DSM-III diagnoses. The average age of the 103 men interviewed was between 25 and 30 years (Motiuk \& Porporino, 1992). Lifetime prevalence rates, rather than present state diagnoses, were reported. This Canadian study found that none of the sex offenders had organic disorder, $6 \%$ suffered from psychosis, and $43 \%$ had antisocial personality disorder. We found lower rates of antisocial personality disorder $(5 \%)$ in the sex offenders in our study, a non-specific finding that also applies to the non-sex offenders.

The GMS has been used to diagnose psychotic illness and dementia in the community, and previous studies in the UK have found that $2 \%$ have a psychotic illness and $1 \%$ have dementia in men aged 65-69 (Copeland et al. 1992; CFAS MRC, 1998). A systematic review of the prevalence of major depression in the community elderly using DSM criteria found prevalence rates between $0.4 \%$ and $3.7 \%$ (Beekman et al. 1999). In the Epidemiologic Catchment Area study of 2106 community elderly, $0 \cdot 2-0 \cdot 8 \%$ were diagnosed with DSM antisocial personality 
disorder (Robins et al. 1984). Therefore, compared with elderly persons living in the community reported in other studies, the rate of psychotic illness, major depression and antisocial personality disorder (but not dementia) is increased in elderly sex offenders. However, these are non-specific findings, applying equally to elderly non-sex offenders. The prevalence of dementia appears to be similar in the elderly sex offenders reported in this study compared with previous community studies. However, it remains possible that men with dementia perform higher rates of aberrant sexual behaviour than other elderly men but that it is not regarded as a sex offence, is not prosecuted, is not considered severe enough to warrant a prison sentence, or is diverted from the criminal justice system on sentencing.

We are not aware of any research on personality in sex offenders that uses the personality trait dimensions of the DSM. Our results accord with one study using the Eysenck Personality Questionnaire in which sex offenders were found to be more introverted than violent offenders (Gudjonsson \& Sigurdsson, 2000). Our findings of increased schizoid, obsessivecompulsive, and avoidant personality traits support the view of Soothill and others (1976) that sex offending is a manifestation of a 'longlasting Achilles heel'. This is normally kept in check by compensatory satisfactions or pressures, but liable to re-emerge in times of stress, such as retirement and physical illness. The social detachment and restricted emotionality that feature in schizoid personality, and the social inhibition and inadequacy of avoidant personality, would also fit into Finkelhor's influential model of child sex offending in that these personality factors may prevent or 'block' the creation of normalising peer relationships, and may explain why the sex offender emotionally relates with children, what Finkelhor terms 'blockage' and 'emotional congruence' respectively (Finkelhor \& Araji, 1986).

We thank Mary Piper, David Hiller, Mike Longfield, Hassan Hassan and Chris Cullen of the Home Office of England and Wales for practical advice and assistance. We are grateful to all the governors, medical staff, and prison officers in the prisons visited for their help, and all the prisoners who took part in the study. John Danesh and Pat Yudkin gave valuable epidemiological advice. Bart Sheehan commented helpfully on an earlier draft of the paper. Lynda Barnes provided secretarial and administrative assistance. This project was funded by the Wellcome Trust (Grant ref. no. 05/584/2/97/2). There have been no previous presentations on this paper.

\section{REFERENCES}

Abel, G., Becker, J., Cunningham-Rathner, J., Mittelman, M. \& Rouleau, J.-L. (1988). Multiple paraphilic diagnoses among sex offenders. Bulletin of the American Academy of Psychiatry and Law 16, 153-168.

Ames, D., Flynn, E., Tuckwell, V. \& Harrigan, S. (1994). Diagnosis of psychiatric disorder in elderly general and geriatric hospital inpatients: AGECAT and DSM-III-R compared. International Journal of Geriatric Psychiatry 9, 627-633.

Beekman, A., Copeland, J. \& Prince, M. (1999). Review of community prevalence of depression in later life. British Journal of Psychiatry 174, 307-311.

Brennan, P., Mednick, S. \& Hodgins, S. (2000). Major mental disorders and criminal violence in a Danish birth cohort. Archives of General Psychiatry 57, 494-500.

CFAS MRC (1998). Cognitive function and dementia in six areas of England and Wales: the distribution of MMSE and prevalence of GMS organicity level in the MRC CFA study. Psychological Medicine 28, 319-335.

Clark, C. \& Mezey, C. (1997). Elderly sex offenders against children: a descriptive study of child sex abusers over the age of 65 . Journal of Forensic Psychiatry 8, 357-369.

Copeland, J. \& Dewey, M. et al. (1992). Geriatric Mental StateAGECAT: prevalence, incidence and long-term outcome of dementia and organic disorders in the Liverpool study of continuing health in the community. Neuroepidemiology 11 (suppl. 1), 84-87.

Copeland, J., Dewey, M., Henderson, A., Kay, D., Neal, C., Harrison, M., McWilliam, C., Forshaw, D. \& Shiwach, R. (1988). The Geriatric Mental State (GMS) used in the community: replication studies of the computerized diagnosis AGECAT. Psychological Medicine 18, 219-223.

Fazel, S., Hope, T., O’Donnell, I. \& Jacoby, R. (2001). Hidden psychiatric morbidity in elderly prisoners. British Journal of Psychiatry 179, 535-539.

First, M., Gibbon, M., Spitzer, R., Williams, J. \& Benjamin, L. (1997). Structured Clinical Interview for DSM-IV Axis II Personality Disorders. American Psychiatric Press: Washington, DC.

Finkelhor, D. \& Araji, S. (1986). Explanations of pedophilia: a four factor model. Journal of Sex Research 22, 145-161.

Folstein, M., Folstein, S. \& McHugh, P. (1975). 'Mini-Mental State': a practical method for grading the cognitive state of patients for the clinician. Journal of Psychiatric Research 12, 189-198.

Greenfield, L. (1997). Sex Offenses and Offenders: An Analysis of Data of Rape and Sexual Assault. Bureau of Justice Statistics, US Department of Justice: Washington, DC.

Gudjonsson, G. \& Sigurdsson, J. (2000). Differences and similarities between violent offenders and sex offenders. Child Abuse and Neglect 24, 363-372.

Gunn, J., Maden, A. \& Swinton, M. (1991). Treatment needs of prisoners with psychiatric disorders. British Medical Journal 303, 338-341.

Home Office (1998). Prison statistics obtained on personal request from Prison Research and Statistics Group, Research, Development and Statistics Directorate, Home Office, London, December 1998.

Henn, F., Herjanic, M. \& Vanderpearl, R. (1976). Forensic psychiatry: profiles of two types of sex offenders. American Journal of Psychiatry 133, 694-696. 
Hucker, S. \& Ben-Aron, M. (1985). Elderly sex offenders. In Erotic Preference, Gender Identity, and Aggression in Men: New Research Studies (ed. R. Langevin), pp. 211-223. Lawrence Erlbaum Associates: London.

Hucker, S., Langevin, R., Dickey, R., Handy, L., Chambers, J. \& Wright, S. (1988). Cerebral damage and dysfunction in sexually aggressive men. Annals of Sex Research 1, 33-47.

Jacoby, R. (1997). Psychiatric aspects of crime and the elderly. In Psychiatry in the Elderly (ed. R. Jacoby and C. Oppenheimer), pp. 749-760. Oxford University Press: Oxford.

McElroy, S., Soutullo, C., Taylor, P., Nelson, E., Beckman, D., Brusman, L., Ombaba, J., Strakowski, S. \& Keck, P. (1999). Psychiatric features of 36 men convicted of sexual offenses. Journal of Clinical Psychiatry 60, 414-420.

Mezey, G., Vizard, E., Hawkes, C. \& Austin, R. (1991). A community treatment programme for convicted child sex offenders: a preliminary report. Journal of Forensic Psychiatry 2, 11-25.

Motiuk, L. \& Porporino, F. (1992). The Prevalence, Nature and Severity of Mental Health Problems among Federal Male Inmates in Canadian Penitentiaries. Report No. 24. Correctional Service of Canada: Ottawa.

O'Carroll, R. (1995). The assessment of premorbid ability: a critical review. Neurocase 1, 83-89.
Office of Population Censuses and Surveys (1993) 1991 Census. HMSO: London.

Robins, L., Helzer, J., Weissman, M. \& Orvaschel, H. (1984) Lifetime prevalence of specific psychiatric disorders in three sites. Archives of General Psychiatry 41, 949-958.

Salter, A. (1988). Treating Child Sex Offenders and Victims. Sage Publications: London.

Seghorn, T., Prentky, R. \& Boucher, R. (1987). Childhood sexual abuse in the lives of sexually aggressive offenders. Journal of the American Academy of Child and Adolescent Psychiatry 26, 262-267.

Soothill, K., Jack, A. \& Gibbens, T. (1976). Rape: a 22-year cohort study. Medicine, Science and the Law 16, 62-69.

Tilhonen, J., Isohanni, M., Rasanen, P., Koiranen, M. \& Moring, J. (1997). Specific major mental disorders and criminality: a 26-year prospective study of the 1966 Northern Finland birth cohort. American Journal of Psychiatry 154, 840-845.

Singleton, N., Meltzer, H. \& Gatward, R. (1998). Psychiatric Morbidity among Prisoners in England and Wales. The Stationery Office: London.

Uzoaba, J. (1998). Managing Older Offenders: Where do we Stand? Report No. 70. Correctional Service of Canada: Ottawa.

Zonana, H. (1997). The civil commitment of sex offenders. Science 278, 1248-1249. 